\title{
GEOLOGIA E PALEONTOLOGIA DO MEMBRO TAQUARAL (EOPERMIANO) NO AFLORAMENTO DO RIO DA CABEÇA, ESTADO DE SÃO PAULO
}

10.18190/1980-8208/estudosgeologicos.v30n1p19-30

Artur Chahud

Universidade de São Paulo, Instituto de Geociências, Departamento de Geologia Sedimentar e Ambiental. Rua do Lago, 562. Cidade Universitária 05508900 - São Paulo, SP - Brasil. e-mail: arturchahud@yahoo.com

\section{RESUMO}

A Formação Irati, Permiano (Cisuraliano) da Bacia do Paraná, destaca-se por importantes características geológicas e paleontológicas. Dois membros são reconhecidos, Taquaral e Assistência. A maior parte do Membro Taquaral é constituída de sedimentos sílticoargilosos, cinzentos, com laminações plano-paralelas e na base ocorrem arenitos conglomeráticos com grande quantidade de fósseis de vertebrados. O afloramento do Rio da Cabeça tem a maior espessura da camada arenosa, $43 \mathrm{~cm}$, os outros possuem 9,5 e $15 \mathrm{~cm}$ de espessura, mas é o que tem menor densidade fóssil, 0,5 fóssil $/ \mathrm{cm}^{2}$. O presente trabalho discute e caracteriza a tafonomia e a paleoictiofauna deste afloramento. A maior parte dos fósseis são dentes, escamas e de partes ósseas indeterminadas desarticuladas e dispersas de Actinopterygii (Palaeonisciformes) e dentes de Chondrichthyes Xenacanthiformes indeterminados.

Palavras chave: Cisuraliano; Chondrichthyes; Actinopterygii; Formação Irati

\begin{abstract}
The Irati Formation, Permian (Cisuralian) of the Paraná Basin, stands out for important geological and paleontological characteristics. Two members are recognized, Taquaral and Assistência. Most of the Taquaral Member is composed of silty-clayey, gray sediments with plane-parallel laminations and at the base there are conglomeratic sandstones with large numbers of vertebrate fossils. The Cabeça River outcrop has the greatest thickness of the sandy facies, $43 \mathrm{~cm}$, the others are 9.5 and $15 \mathrm{~cm}$ thick, but the lowest fossil density, 0,5 fossil $/ \mathrm{cm}^{2}$. The present work discusses and characterizes the taphonomy and paleoictiofauna of this outcrop. Most fossils are teeth, scales and indeterminate bone parts of Actinopterygii (Palaeonisciformes) and indeterminate Xenacanthiformes teeth.
\end{abstract}

Keywords: Cisuralian; Chondrichthyes; Actinopterygii; Irati Formation

\section{INTRODUÇÃO}

A Formação Irati (Cisuraliano) é uma das mais famosas unidades geológicas da Bacia do Paraná devido ao seu conteúdo fossilífero de peixes, vegetais, microfósseis, crustáceos e répteis (Mezzalira, 1989, 2000). Atualmente a unidade é dividida em dois membros, Taquaral (base) e Assistência (topo) (Barbosa \& Gomes, 1958; Milani et al. 2007; Holz et al. 2010). O Membro Taquaral é dividido em duas fácies principais, a arenosa, ocorrendo principalmente na parte basal da unidade (Chahud \& Petri, 2010a), e a de folhelho 
síltico, predominante na unidade (Chahud \& Petri, 2013a, 2013b).

O presente trabalho foi realizado na fácies arenosa do Membro Taquaral (Fig. 2). Esta fácies é caracterizada por quartzo - arenito conglomerático de espessura da ordem de centímetros (5$100 \mathrm{~cm})$, constituído de grânulos e seixos de sílex em matriz arenosa variando de média a fina. Os grânulos e seixos, angulosos e arredondados, estão ou não em contato entre si. $\mathrm{O}$ acamamento é, em geral, lenticular com estratificações cruzadas ou ondulações e grande quantidade de ictiofósseis de diferentes tamanhos e estados de preservação.

Tais depósitos contêm grande abundância de dentes, escamas e outros restos de vertebrados (Ragonha, 1978; Chahud \& Petri, 2008a; 2008b; 2009; 2014; Chahud et al. 2010b; 2012). Os fósseis, em geral, são pequenos e fortemente cimentados à matriz de arenito fino. Em observações feitas por
Chahud \& Petri (2015b), há variações litológicas, abundância e preservação dos fósseis.

O objetivo deste trabalho é a caracterização paleontológica e tafonômica da base arenosa do Membro Taquaral no Afloramento do Rio da Cabeça, divisa entre os municípios de Rio Claro e Ipeúna, Estado de São Paulo.

\section{LOCALIZAÇÃO E CONTEXTO GEOLÓGICO}

$\mathrm{O}$ afloramento tem quatro metros de comprimento e ao menos de 2 metros de altura (a partir da margem do rio até a altura da estrada), localiza-se na entrada do Sitio Santa Maria, exatamente na divisa entre os municípios de Ipeúna e Rio Claro (UTM: 23K 227300/7517325) (Fig.1). Situa-se na margem sul de um córrego afluente do Rio da Cabeça, em que se observam três fácies de estruturas e litologias diferenciadas (Fig. 2)

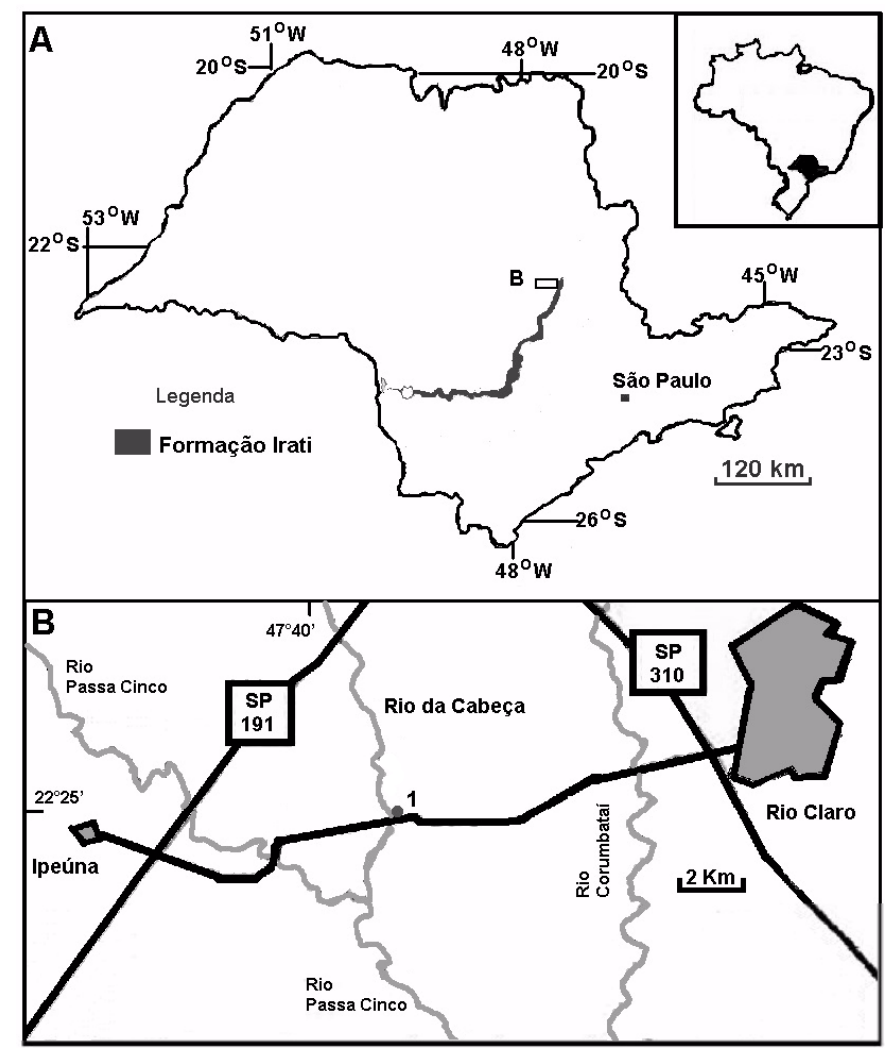

Figura 1 - A) Afloramentos da base da Formação Irati no centro-leste do Estado de São Paulo. B) Região de Rio Claro e Ipeúna; 1) Localização do Afloramento do Rio da Cabeça. 


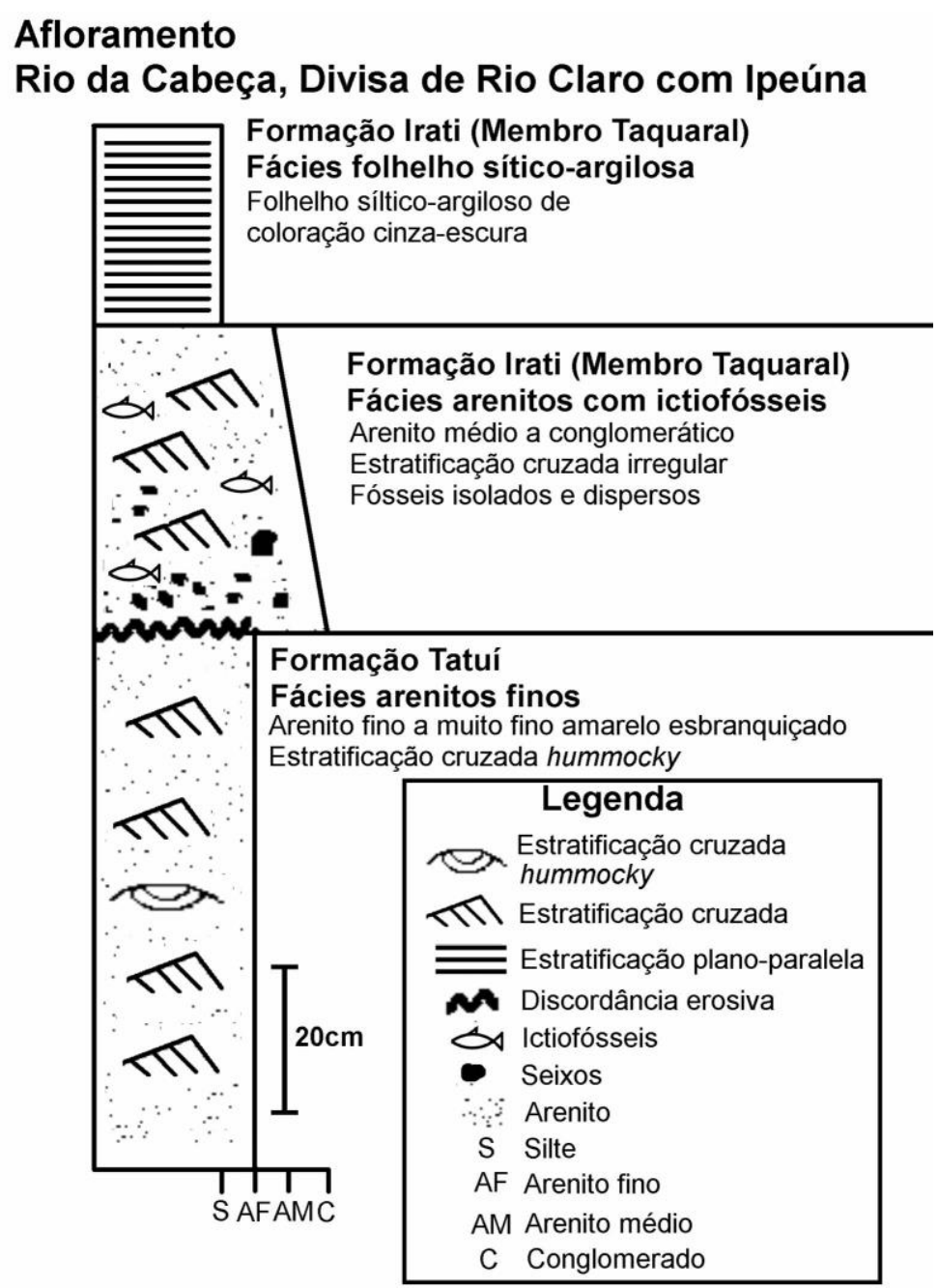

Figura 2 - Seção estratigráfica do Afloramento do Rio da Cabeça.

A fácies basal do afloramento, afossilífera, caracteriza-se por arenito fino a muito fino, bem selecionado e de coloração amarelada para esbranquiçada. Uma parte é submersa no afluente do Rio da Cabeça e outra emersa. Foram observadas grandes estratificações cruzadas do tipo "hummocky" de grande porte $(1 \mathrm{~m}$ de tamanho), que mergulha para dentro do afluente do Rio da Cabeça. O contato com a camada sobrejacente é abrupto e marcado por uma discordância erosiva.

A camada principal do presente estudo, base do Membro Taquaral, e de importância paleontológica pela sua diversidade e abundância apresenta diferenças estratigráficas e faciológicas para outras localidades, previamente estudadas (Chahud \& Petri, 2010a; 2015a e CHAHUD, 2011). É uma camada tabular com mergulho de 10 graus NE (N45W/10NE), muito maior do que a observada em outros afloramentos (próximo de 3 graus de mergulho), e $43 \mathrm{~cm}$ de espessura, muito mais espessa que todos os outros afloramentos estudados na região (8 - 15 $\mathrm{cm}$ de espessura) (Chahud \& Petri, 2010a; 2015a).

Apesar da diferença de espessura a composição sedimentológica é similar a observada em outras localidades (Chahud et al. 2012; Chahud \& Petri, 2010a; 2015a; 2015b), representados por arenitos finos a médios, conglomeráticos, com clastos de origem biológica, coprólitos e restos ósseos, ou 
inorgânicos, sílex e quartzo. A granulometria varia de grânulos a calhaus, estes últimos observados apenas na base. Granodecrescência ascendente, inclusive dos clastos que desaparecem à medida que se sobe na estratigrafia.

A estratificação é irregular com diversos sentidos de corrente. Foram constatadas estratificações cruzadas na base e no topo com mais de $10 \mathrm{~cm}$, dando falsa impressão de camadas diferenciadas. Verificam-se variações de cores no tom acinzentado, mais claros em porções mais grossas e mais escuras nas camadas mais finas.

Parte do afloramento está silicificada, atribuída à atividade ígnea, visto a presença de diabásio "in-situ", que pode ter causado parte do soerguimento da camada e criando um mergulho mais acentuado, porém os fósseis não foram afetados

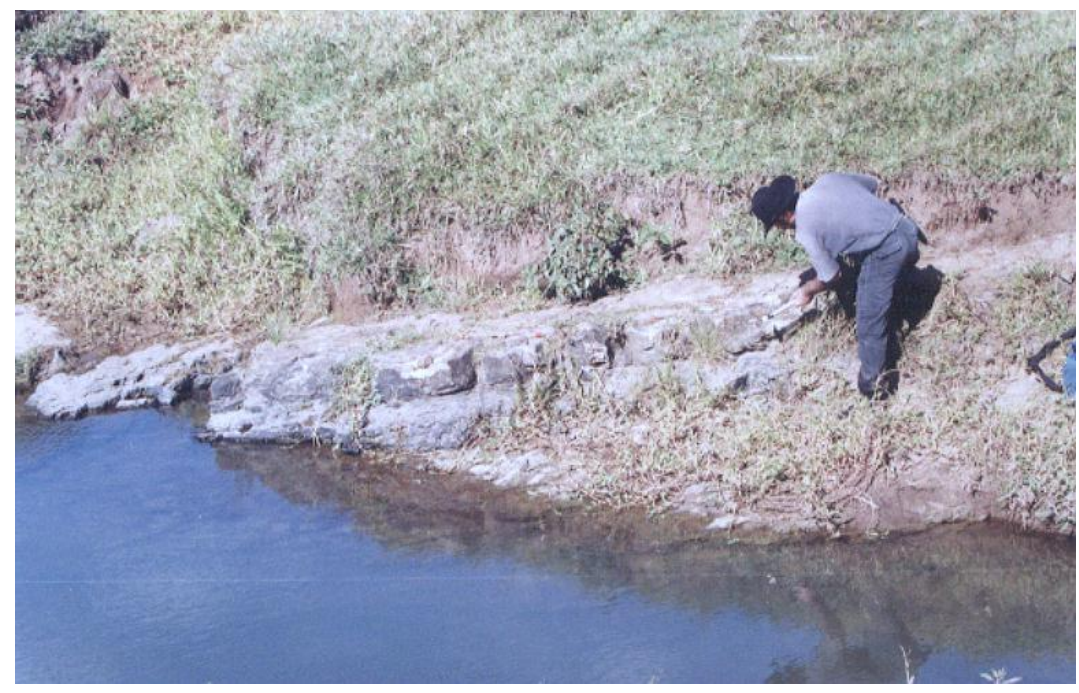

Figura 3 - Afloramento do Rio da Cabeça. Destaque para a fácies basal do Membro Taquaral, de coloração acinzentada.

A fácies síltica-argilosa do Membro Taquaral é residual e está muito alterada neste afloramento, porém é possível observar a coloração cinzaescura (quando menos alterada), com laminação plano-paralela. Não foram observados fósseis neste ponto, apesar de terem sido registrados em outras localidades (Chahud \& Petri, 2013a; 2013b).

\section{MATERIAL E MÉTODOS}

O material é representado basicamente por escamas, dentes e partes ósseas de peixes. Os espécimes estudados estão depositados na Coleção Científica do Laboratório de Paleontologia Sistemática do Instituto de
Geociências da Universidade de São Paulo.

Os estudos tafonômicos da paleoictiofauna realizadas na base da Formação Irati utilizaram as mesmas técnicas padronizadas para afloramentos da região e desenvolvidas por Chahud \& Petri (2015b). Vinte amostras de mão foram coletadas para o estudo de assinaturas tafonômicas em laboratório. O exame destas amostras foi suficiente para obter dados representativos referentes à densidade espacial, presença ou não de agregados/acumulações fósseis e seleção de partes ósseas (Chahud, 2011, Chahud \& Petri, 2015a, 2015b).

Foram medidos quadrados de um centímetro de cada lado em amostras de 
tamanho similar. Nas análises e estudos relacionados ao arranjo e densidade espacial, foram selecionados os fósseis de tamanho superior a $0,5 \mathrm{~mm}$ de comprimento, pois espécimes menores não ofereciam margem de segurança na diferenciação de fósseis vertebrados de outros materiais orgânicos não identificáveis e inorgânicos de coloração e formato semelhantes.

\section{CARACTERIZAÇÃO TAFONÔMICA}

O número de táxons no afloramento do Rio da Cabeça é baixo comparado aos afloramentos próximos descritos na literatura (Ragonha, 1978; Chahud et al. 2010; Chahud \& Petri, 2014) e a densidade espacial dos fósseis, 0,5fóssil $/ \mathrm{cm}^{2}$, é uma das menores na região (Chahud \& Petri 2015a; 2015b).

Os grupos encontrados no afloramento incluem duas ordens de Chondrichthyes, Xenacanthiformes e Petalodontiformes, e uma de Actinopterygii, Palaeonisciformes (parafilético). Os Chondrichthyes são muito raros e pode se concluir que o afloramento é composto principalmente de dentes e escamas de Palaeonisciformes.

Não existe orientação dos fósseis em planta (Fig. 4), com diversas direções. Em perfil, dentes e espinhos normalmente estão concordantes ao acamamento (Fig. 5), porém é possível observar alguns com pequena obliquidade em relação à camada. Agregados e acumulações pontuais não foram observados.

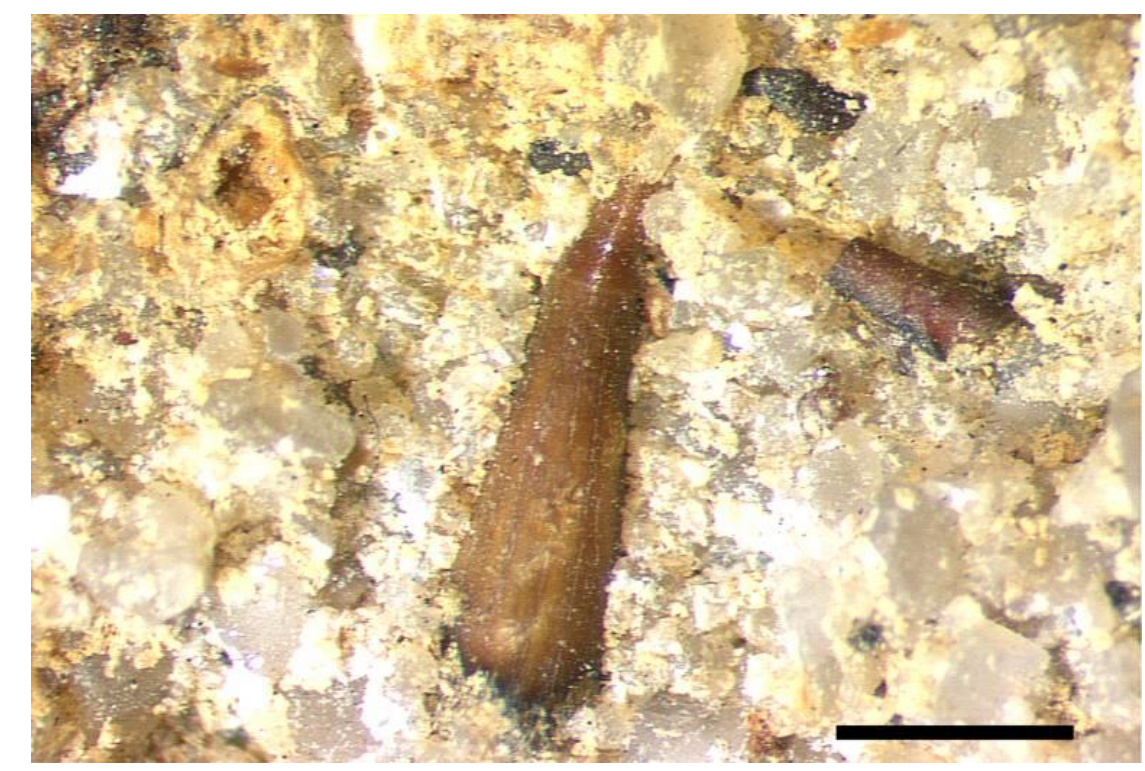

Figura 4 - Vista em planta destacando dentes de paleoniscideos em diferentes posições. Escala 1mm. 


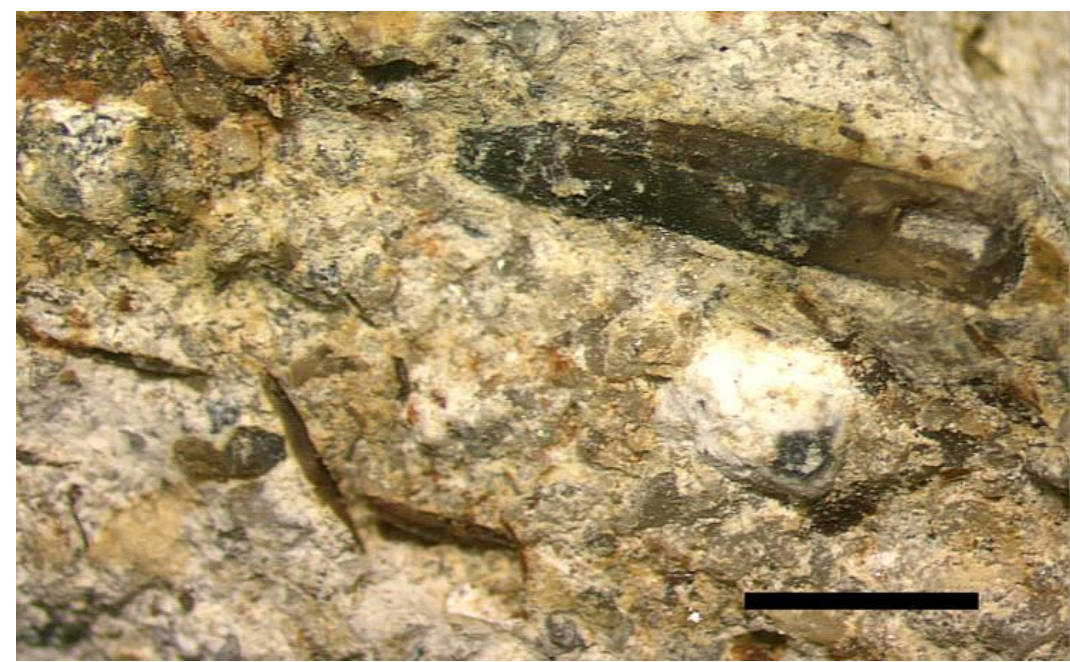

Figura 5 - Vista em perfil mostrando ossos e dentes concordantes e oblíquos. Escala $2 \mathrm{~mm}$.

O material fóssil é representado predominantemente por escamas e dentes completos e poucas quebras. Os fósseis estão mal selecionados em tamanho, desarticulados, e dispersos na rocha, sem a possibilidade de associação entre as partes ósseas.

Muitos dentes e escamas de Palaeonisciformes, de tamanho variado, foram encontrados inteiros, associados a fragmentos com muito desgaste e polimento, caracterizando mistura de elementos em diferentes estados de preservação.

\section{XENACANTHIFORMES}

Os Xenacanthiformes são muito raros neste afloramento e representados por três indivíduos, dois muito desgastados, como observado na Fig. 6, e outro, GP/2E-6456, em melhor estado de preservação (Fig. 7) que representam as formas incomuns e mais raras da família Xenacanthidae (Chahud \& Petri, 2009).

O gênero Taquaralodus (Chahud \& Petri, 2010b), Xenacanthiformes mais comum da unidade, não foi, até o momento, encontrado neste afloramento, porém como a densidade espacial neste afloramento é menor, a presença não deve ser descartada, porém é possível inferir que era menos comum que os Xenacanthidae.

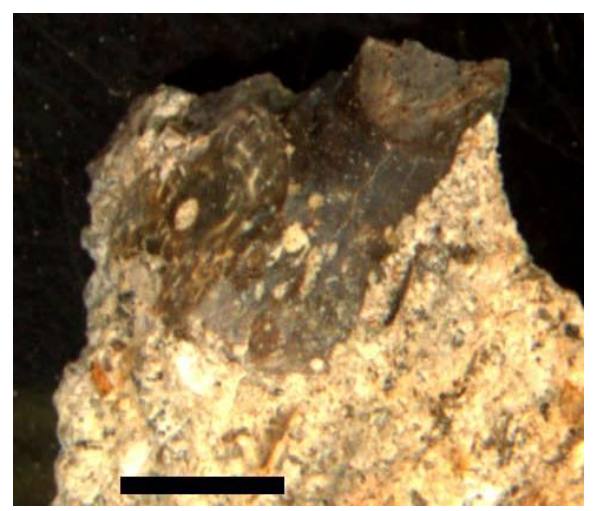

Figura 6 - Maior exemplar de Xenacanthidae indeterminado, fragmentado, encontrado no Afloramento 3. Escala $1 \mathrm{~mm}$. 
O dente GP/2E-6456 é composto por duas cúspides laterais principais e vestígios de cúspide intermediária, todas em contato direto. As cúspides principais estão fragmentadas, mas é possível observar que são arredondadas em corte transversal. A cúspide intermediária, menor em diâmetro, também está fragmentada e possui aproximadamente metade do diâmetro das maiores. Todas as cúspides estão localizadas na face labial.

A base apresenta quebras pequenas, mas é possível observar o formato arredondado ou quadrangular. Ocorrem foramens nutritivos na parte superior lingual, próximos do botão apical, nas laterais e face inferior. Não foi observada depressão significativa na face inferior da base. O tubérculo basal está muito desgastado e incrustações prejudicaram a análise.

O botão coronal é circular, não tem contato com as cúspides e está posicionado na face lingual da base.

A base tem $1,0 \mathrm{~mm}$ de comprimento tanto anterior - posterior quanto na distância labial - lingual. A cúspide maior tem $0,8 \mathrm{~mm}$ de altura. $\mathrm{O}$ botão coronal possui, aproximadamente, $0,5 \mathrm{~mm}$ de comprimento máximo.

Não se sabe a que Xenacanthiformes pertence, mas não era um Taquaralodus, (Chahud \& Petri, 2010b) ou um Xenacanthus (Chahud \& Petri, 2009), mas provavelmente seja uma espécie nova indeterminada de Xenacanthidae, como as descritas por Chahud \& Petri (2009)

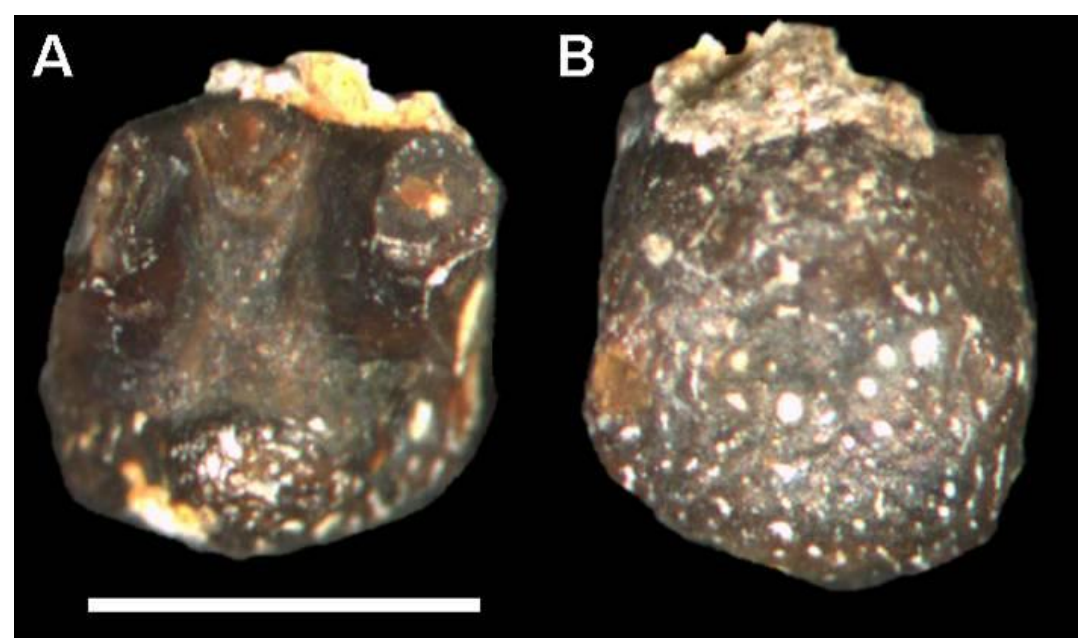

Figura 7 - Exemplar GP/2E-6456 de Xenacanthidae indeterminado do Afloramento 3. A) Vista oclusal; B) Vista inferior. Escala 1mm.

\section{DIVERSIDADE ICTIOLÓGICA E PALAEONISCIFORMES}

A diversidade de Chondrichthyes é grande observando o número de espécies e grupos observados nos afloramentos da região e, aparentemente, pode ser maior que a de Actinopterygii, do tipo Palaeonisciformes.

Os Paleonisciformes formam um grupo parafilético de actinopterígeos, representativos de sete famílias, com parentesco duvidoso, de grande sucesso no Paleozóico (Richter et al. 2004). A ordem surgiu no Siluriano e continuou durante o Mesozóico com poucos representantes até o Cretáceo.

Praticamente todos os

Palaeonisciformes apresentavam um padrão básico de desenvolvimento, com grandes bocas, olhos colocados na face anterior do crânio e escamas ganóides rígidas e primitivas com baixa diversidade e baixa variação 
morfológica. As nadadeiras aparentemente seguiam o mesmo padrão, tanto anal quanto dorsal, está única de bases longas, e a cauda heterocerca.

Os Palaeonisciformes são homodontes e seus dentes consistem basicamente de uma fuste de formato cônico, com um capuz apical no ápice. A superfície da fuste pode ser lisa ou ornamentada por costelas ou pequenos tubérculos. São constituídos, internamente, por ortodentina com uma camada de esmalte envolta (ganoína de colar). Em geral, o capuz apical é maciço e composto de um material resistente, acrodina (um enamelóide).

As escamas nos Palaeonisciformes são do tipo ganóide, com formato romboédrico, constituição rígida e sistema articulatório (peg-and-socket). Apresentam uma camada basal de osso lamelar celular, uma camada de dentina (ortodentina) e uma cobertura de esmalte de origem ectodérmica (ganoína).

Apesar da abundância de Palaeonisciformes, a identificação de espécies somente é possível em exemplares completos ou semicompletos, dada a baixa variação morfológica externa entre os diversos gêneros.

Würdig-Maciel (1975), Richter (1980) e Richter et al. (1985) sugeriram uma associação de diversas escamas a determinados gêneros neopaleozóicos e ressaltaram a grande variedade morfológica interna e externa de dentes Palaeonisciformes do Grupo Passa Dois do Rio Grande do Sul.

Würdig-Maciel (1975) e Richter et al. (1985) sabendo que não poderiam classificar os dentes em espécies, desenvolveram uma classificação artificial com finalidades bioestratigráficas, na qual foram levados em conta caracteres diagnósticos e básicos, como, por exemplo, a curvatura ou não dos dentes e a presença de costelas no capuz apical ou na fuste. Richter et al. (1985), em revisão, chegaram a 10 classes morfológicas de ictiodontes (I); dentes retos lisos e costelados, I-1 e I-2; dentes curvos lisos e costelados, I-3 e I-4; dente curvo de rugosidade na fuste, I-5; dentes sigmoidais (ou forma de $\mathrm{S}$ ) lisos e costelados, I-6 e I-7; dentes com a fuste tuberculada, I-8 a I-10.

A classificação infelizmente só tem valor em unidades de deposição lenta, pois a análise é prejudicada em depósitos de alta energia com dentes quebrados ou fragmentados, por exemplo; as quebras de dentes sigmoidais poderiam gerar fragmentos que seriam identificados erroneamente como dentes curvos simples (Chahud \& Petri, 2008b).

No presente estudo, ao contrário dos exemplares da região Sul que praticamente não exibem indícios de abrasão, os fósseis da base da Formação Irati sofreram desgaste superficial e quebras, o que dificulta a diferenciação, especialmente, entre dentes sigmóides e curvos e também a constatação de microtubérculos na fuste devido ao polimento causado pela abrasão, limitando a comparação.

Algumas formas de dentes de Palaeonisciformes possuem características morfológicas externas variadas no formato da fuste como: espessura de costelas e robustez ou afinamento do dente, que não foram previstas ou consideradas por Würdig-Maciel (1975) e Richter et al. (1985).

O exemplar GP/2E-6412 (Fig. 8) exibe a região inferior da fuste com uma largura muito maior que o resto do dente. O espécime é curvo apenas em sua parte inferior, próximo da inserção com a mandíbula. Apresenta espessas costelas que se afinam próximo do ápice. O capuz apical com menos de $0,5 \mathrm{~mm}$ é pequeno e liso. 


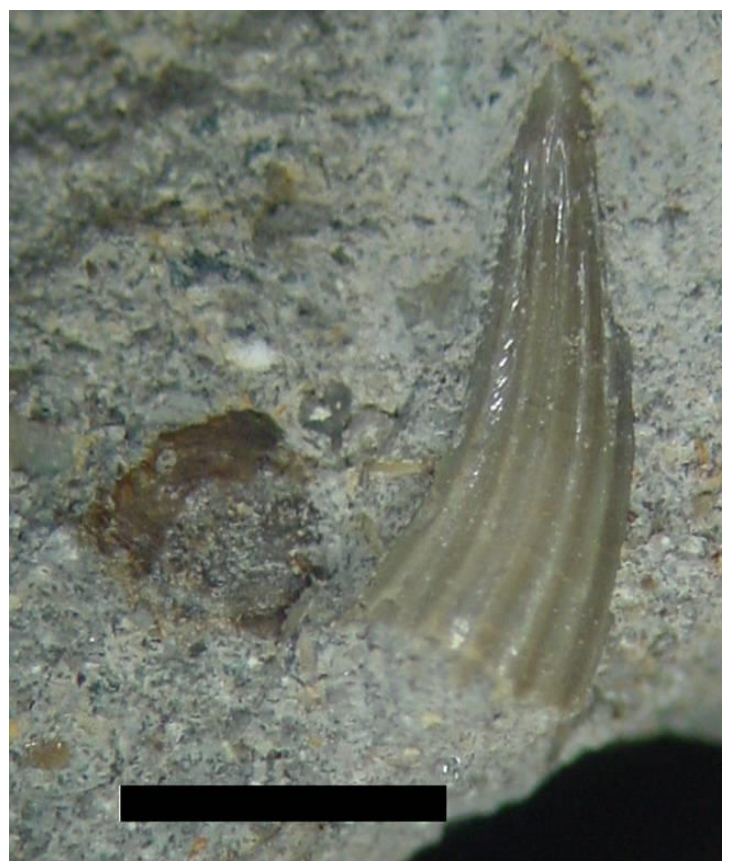

Figura 8 - Dente de Palaeonisciformes curvo de base espessa GP/2E-6412. Escala 2mm.

Dentes muito finos e alongados são mais raros (Fig. 9). Foram observados apenas dois exemplares. $\mathrm{O}$ exemplar GP/2E-6409 (Fig. 9B) é o maior observando-se a ausência de costelas, disposição reta e com capuz apical liso, apesar de parte da superfície estar desgastada. O comprimento total deste exemplar é de $3,5 \mathrm{~mm}$.

O exemplar GP/2E-6450 (Fig. 9A) é um espécime com pouco mais de $2 \mathrm{~mm}$ de comprimento e possuindo as mesmas características do exemplar GP/2E-6409.

Exemplares de porte centimétrico, curvos, de costelas muito finas, são comuns, em exemplares menores, estas costelas apresentam-se como linhas finas por toda a superfície. O exemplar GP/2E-6389 (Fig. 10) de, aproximadamente, $2 \mathrm{~mm}$ de comprimento é curvo, com finas linhas em sua superfície. Na fuste também podem ser observadas linhas transversais ao dente.

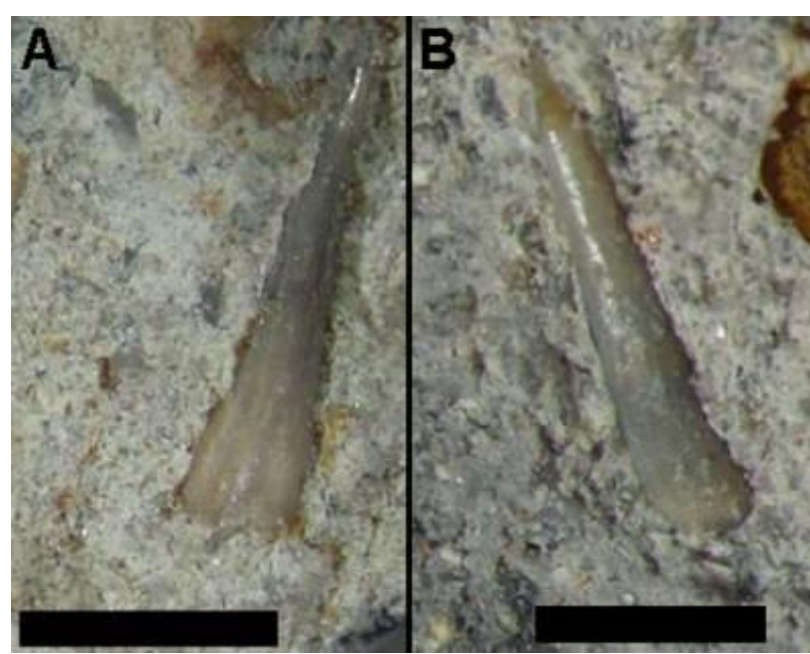

Figura 9 - Dentes retos muito alongados A) GP/2E-6450, escala 2mm; B) GP/2E-6409, escala $1 \mathrm{~mm}$. 


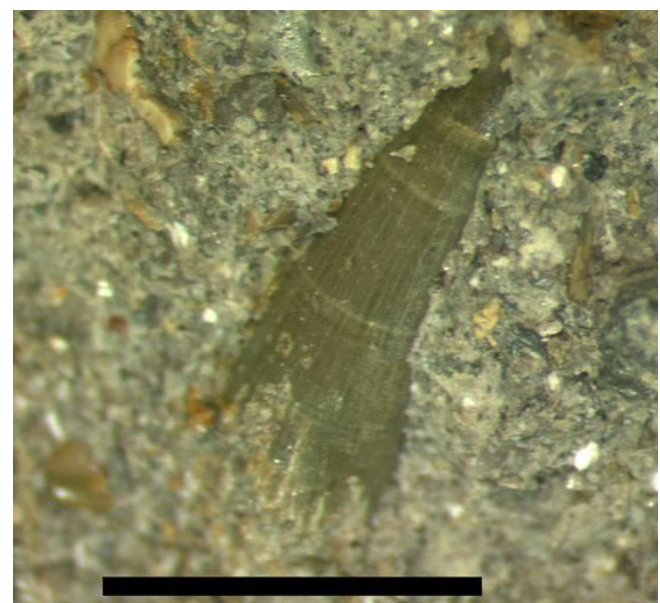

Figura 10 - Dente de Palaeonisciformes (GP/2E-6389) com finas linhas na superficie da cúspide. Escala $2 \mathrm{~mm}$.

As observações de novas texturas e configurações nos dentes de Palaeonisciformes são comuns em todos os afloramentos estudados da base do Membro Taquaral, incluindo o do Rio da Cabeça, e sugerem maior diversidade deste grupo, mesmo espécies não sendo conhecidas.

Entre as variedades possíveis de Palaeonisciformes baseada em dentes é possível destacar as seguintes combinações possíveis: sem dentes, dentes retos, curvos ou sigmoidais, dentes robustos ou finos, dentes lisos ou costelados, estes podem ter costelas finas ou espessas, ornamentação e formato variado ou irregular e com microtubérculos em sua superfície.

Inicialmente é possível prever dezenas de combinações $(>20)$, que estaria de acordo com a relação Actinopterygii e Chondrichthyes recentes, que em tempos modernos representam $89,6 \%$ das espécies para o primeiro e apenas $3 \%$ para o segundo (Nelson, 2006). Contudo no Paleozóico essa relação era equivalente com maior número de espécies de Chondrichthyes em relação aos Actinopterygii (Lund et al. 2012) e o fator dessa maior abundância de Actinopterygii deve-se ao fato de que escamas, dentes e partes ósseas de Palaeonisciformes são mais resistentes, abundantes e fáceis de serem preservadas se comparadas com os restos de Chondrichthyes e, por isso, essa comparação em número de espécies deve ser feita com reservas.

\section{CONCLUSÕES}

O afloramento do Rio da Cabeça foi o que mostrou a maior espessura da fácies arenosa da base do Membro Taquaral na região, $43 \mathrm{~cm}$ enquanto outros afloramentos da variam de $8-15$ $\mathrm{cm}$, porém não possui a maior diversidade e riqueza fossilífera de Chondrichthyes e a densidade espacial dos fósseis, de 0,5 fóssil $/ \mathrm{cm}^{2}$, é uma das menores entre os afloramentos da região.

Apesar da baixa riqueza de espécies de Chondrichthyes o afloramento possui uma variedade de Xenacanthiformes rara em outras localidades e não apresentou, até o momento, a presença de Taquaralodus, fóssil mais abundante desse grupo, sugerindo provavelmente um ambiente diferenciado de outros locais.

Restos de Palaeonisciformes são muito abundantes, na forma de escamas e dentes, mas não é possível a identificação de espécies ou mesmo de famílias. Contudo a grande variedade morfológica de dentes sugere uma diversidade considerável de espécies e que ela pode ser tão grande ou maior que a de Chondrichthyes. 
Agradecimentos

O autor expressa seu agradecimento ao Prof. Dr. Thomas Rich Fairchild e ao Prof. Dr. Setembrino Petri, pelo apoio e auxílio dados em vários momentos durante esta pesquisa, aos proprietários do Sítio Santa Maria no município de Rio Claro, Senhor Luis e Senhora Bernardete, onde foi coletado o material, ao Departamento de Geologia Sedimentar e Ambiental que permitiu que os trabalhos de preparação dos fósseis fossem realizados em seus laboratórios.

\section{REFERÊNCIAS}

Barbosa, O., Gomes, F.A. 1958. Pesquisa de petróleo na bacia do rio Corumbataí. Rio de Janeiro, Boletim do DNPM/DGM. 171: 40p.

Chahud, A. 2007. Paleontologia de Vertebrados da Transição entre os grupos Tubarão e Passa Dois no Centro-Leste do Estado de São Paulo. Programa de Pós-graduação em Geologia Sedimentar. IGcUSP. São Paulo. Dissertação de Mestrado. 172p.

Chahud, A. 2011. Geologia e paleontologia das formações Tatuí e Irati no centro-leste do Estado de São Paulo. Tese de Doutorado (inédita). IGc-USP. 299p

Chahud, A., Fairchild, T. R., Petri, S. 2010. Chondrichthyans from the base of the Irati Formation Permian, Parana Basin), São Paulo, Brazil. Gondwana Research, 18, 528-537.

Chahud, A., Pacheco, M. L. A. F., Meira, F. E., Romero, G. R., Petri, S. 2012. Paleontology and depositional environments of the Tatuí and Irati formations (Permian) in the Ponte Nova Farm, Ipeúna, state of São Paulo. Revista
Brasileira de Geociências, 42(1), 198-212.

Chahud, A. \& Petri, S. 2008a. Chondrichthyes no Membro Taquaral, base da Formação Itati, no centro-leste do Estado de São Paulo, Brasil. Revista de Geologia, 21, 169-179.

Chahud, A. \& Petri, S. 2008b. Registro de paleoniscóides na base do Membro Taquaral, Formação Irati, Permiano da Bacia do Paraná. Revista do Instituto Geológico, 29 (1/2), $33-40$.

Chahud, A. \& Petri, S. 2009. Novos Xenacanthidae (Chondrichthyes, Elasmobranchii) da base do Membro Taquaral, Formação Irati, Permiano da Bacia do Paraná. Revista do Instituto Geológico, 30(1/2), 19-24.

Chahud, A. \& Petri, S. 2010a. Anfíbio e Paleonisciformes da Porção Basal do Membro Taquaral, Formação Irati (Permiano), Estado de São Paulo, Brasil. Geologia USP. Série Científica, 10(1), 29-37.

Chahud, A. \& Petri, S. 2010b. O tubarão Taquaralodus albuquerquei (Silva Santos, 1946) do Membro Taquaral (Permiano, Formação Irati) no Estado de São Paulo. Acta Biologica Paranaense, 39, 1-17.

Chahud, A. \& Petri, S. 2013a. Paleontology of Taquaral Member silty shale in the State of São Paulo. Brazilian Journal of Geology. 43, 117-123.

Chahud, A. \& Petri, S. 2013b. The silty shale Taquaral Member of the early Permian Irati Formation (Paraná Basin, Brazil). Paleontology and paleoenvironments. Swiss Journal of Palaeontology. 132, 119-128.

Chahud, A. \& Petri, S. 2014. New chondrichthyans from the Irati Formation (Early Permian, Paraná Basin), Brazil: origin, palaeoenvironmental and 
palaeogeographical

considerations. Proceedings of the Geologists Association, (125), 437-445.

Chahud, A. \& Petri, S. 2015a. Geologia e Paleontologia da Formação Irati (Eopermiano, Bacia do Paraná) no Rio Passa Cinco, Estado de São Paulo. Brazilian Geographical Journal: Geosciences and Humanities research medium. 6(1), 110-120.

Chahud, A. \& Petri, S. 2015b. Geology and Taphonomy from the Base of the Taquaral Member, Irati Formation (Permian, Paraná Basin), Brazil. Acta Geologica Polonica. 65(3), 379-387.

Chahud, A. \& Petri, S. 2016. Paleontologia da fácies arenosa do Membro Taquaral (Permiano) no Estado de São Paulo: estado da arte e contribuições adicionais. Geologia USP. Série Científica. 16(3). 105-115.

Holz, M., França, A.B., Souza, P.A., Iannuzzi, R., Rohn, R. (2010) A stratigraphic chart of the Late Carboniferous/Permian succession of the eastern border of the Paraná Basin, Brazil, South America. Journal of South American Earth Sciences, 29, 381-399.

Lund, R., Greenfest-Allen, E., Grogan. E. D. 2012. Habitat and diversity of the Bear Gulch fish: Life in a 318 million year old marine Mississippian bay. Palaeogeography, Palaeoclimatology, Palaeoecology. 342-343: 1-16.

Mezzalira, S. 1989. Os fósseis do Estado de São Paulo. 2 ed. ver. atual. São
Paulo, Secretaria do Meio Ambiente, Instituto Geológico. Série Pesquisa. 142p.

Mezzalira, S. 2000. Os fósseis do Estado de São Paulo. Parte II. Período 1987 (parcial) - 1996. São Paulo, Instituto Geológico. Boletim do Instituto Geológico, 15, 70 p.

Milani, E. J., Melo, J. H. G., Souza, P. A., Fernandes, L. A., Franca, A. B. 2007. Bacia do Paraná. Boletim de Geociências da Petrobrás, 15, 265287.

Ragonha, E.W. 1978. Chondrichthyes do Membro Taquaral (Formação Irati) no Estado de São Paulo. Dissertação de Mestrado (Inédita). São Paulo. IGc-USP, 65p.

Richter, M. 1980. Ultra-estrutura de dentes de Paleoniscídeos (Pisces) do Grupo Passa Dois, RS, Brasil. Iheringia, Série Geologia., Porto Alegre. (8):131-145.

Richter, M., Piccoli, A.M.M., Lima, M.C.S. $1985 . \quad$ Variação morfológica de restos de paleoniscídeos (Pisces) no Permiano da Bacia do Paraná. In: Coletânea de Trabalhos Paleontológicos. DNPM, Série Geologia. Seção de Paleontologia e Estratigrafia. Brasília. 2(27):111 122.

Richter, M., Viana, M.S.S., Malabarba, M.C.S.L. 2004. Agnatos e Peixes. In: Carvalho. I. S. (eds.) Paleontologia. Rio de Janeiro, Editora Interciência, 1:733-761.

Würdig-Maciel, N.L. 1975. Ichtiodontes $\mathrm{e}$ ichtiodorulitos (Pisces) da Formação Estrada Nova e sua aplicação na estratigrafia do Grupo Passa Dois. Pesquisas, 5, 7-165. 